\title{
BUREAUCRACY 2.0: THE BUREAUCRATIZATION OF PROFESSIONAL WORK
}

\author{
Paul D. Nugent, Western Connecticut State University, nugentp@wcsu.edu
}

\begin{abstract}
In this paper I offer a review of research bearing on the professional worker in bureaucratic forms of organization throughout the twentieth century. I argue that there is an unfortunately poor timing in which by the 1990s scholars believed they had put empirical matters to rest at roughly the same time a systemic shift in bureaucratization was taking hold. Lean, Information Technology Infrastructure Library (ITIL), Six Sigma, and Capability Maturity Model Integration (CMMI) are representative of this bureaucratization and are discussed in order to highlight qualitative shifts in how professional work is performed and evaluated within the organization. I argue that, especially from the professional's point of view, this shift is significant enough to distinguish the earlier bureaucracies from those that have experienced this shift. Borrowing from the Web 1.0 and 2.0 analogy, I refer to bureaucracies that came before as bureaucracy 1.0 and those that have experienced this shift bureaucracy 2.0. Given the nature of this shift, I invite researchers to consider the effect that bureaucracy 2.0 has on professional workers from both critical and practical angles.
\end{abstract}

Keywords: Bureaucracy, Professionals, Critical Theory, Labor Studies, Quality Control, Philosophy of Technology

\section{INTRODUCTION}

This paper explores the ways in which bureaucracies are changing in a manner that may be threatening the professional's latitude and autonomy and therefore the meaningfulness of his or her work. To build this argument, I develop a broad-brush review of research bearing on the professional worker in bureaucratic forms of organization throughout the twentieth century. I claim that there is an unfortunately poor timing in which by the 1990 s scholars believed they had put empirical matters to rest at roughly the same time a systemic shift in bureaucratization was taking hold. Lean, Information Technology Infrastructure Library (ITIL), Six Sigma, and Capability Maturity Model Integration (CMMI) are representative of this new bureaucratic form and are discussed in order to highlight qualitative shifts in how professional work is performed and evaluated within the organization. I argue that, especially from the professional's point of view, this shift is significant enough to distinguish the earlier bureaucracies from those that have experienced this shift.

\section{LITERATURE REVIEW}

\section{Professionals in Bureaucracies (1900 - 1995)}

Max Weber's analysis of bureaucracy has provided scholars with a powerful theoretical framework with which to think about modern organizations, efficiency, and the human condition. The key points that he outlined included fixed jurisdictions for work governed by rules, a hierarchy of authority, written documentation, and extensive training of office-holders (Weber, 1973). Over time scholars have refined these basic traits to:

1. Equal treatment for all employees.

2. Reliance on expertise, skills, and experience relevant to the position.

3. No extraorganizational prerogatives of the position... that is, the position is seen as belonging to the organization, not the person. The employee cannot use it for personal ends.

4. Specific standards of work and output.

5. Extensive record keeping dealing with the work and output.

6. Establishment and enforcement of rules and regulations that serve the interests of the organization.

7. Recognition that rules and regulations bind managers as well as employees; thus employees can hold management to the terms of the employment contract. (Perrow, 1986, p. 3) 
Many seized upon the new independent and dependent "variables" that the bureaucratic form offered to their research. These followed a predominantly "systems" approach to organizations that, consistent with Weber's "iron cage" metaphor, treated the entire entity as a machine. Control lay at the heart of these approaches with some researchers focusing on the effects of behavioral rigidity (Merton, 1940), the role of delegation by management and internalization of goals by participants (Selznick, 1949), visibility of power relations and the replacement of personal rules with impersonal rules (Gouldner, 1954) and optimal spans of control (Hall, 1991). In general, however, the human relations school used the bureaucratic framework to consider how to tweak these variables to increase motivation and job satisfaction (e.g., McGregor 1957, McClelland, 1966).

Critical scholars, on the other hand, were more interested in the potentially negative effects of bureaucracy on the workers. Most of these studies were Marxist studies focusing on the manner in which the modern industrial bureaucracy led to various forms of alienation (esp. deskilling and loss of autonomy) for factory workers (e.g., Roy, 1954; Braverman, 1974; Burawoy, 1979).

In parallel with these studies, there were other researchers who asked how the professional was fairing in this new social structure. After all, professionals possess relatively higher degrees of control over their work, meaningfulness, expertise, education, and less management supervision. Some studies were able to identify correlations between the degree of bureaucratization and the degree of Marxist alienation experienced by the professionals (e.g., Smith, 1971; Bonjean \& Grimes, 1970; Matheson, 2007; Raub, 2008; Tripathi, 1976). However formal bureaucratic control of the professional was found to be minimal and control over their product was achieved through informal organizational and professional norms and alienation, if it was found at all, tended to result from ambiguity and political conflict (e.g., Bailyn, 1985; Becker et. al. 1961; Dalton, 1959; Gouldner, 1954; Jackall, 1988; Kanter, 1977; Kunda, 1992; Roethlisberger \& Dixon, 1939; Rohlen, 1974; Rosen, 1984; Whyte, 1956). In these studies it is not loss of control over one's material labor but rather the chronic tension between the impersonal demands of the bureaucracy for rationality and the actual social reality that organizational life is rife with conflicting expectations, personality, informal culture, and ambiguity. Furthermore, engineers have tended to align their interests with those of management and scientists are often afforded a high degree of latitude as long as they continue to deliver patents, inventions, and innovations (Perrow, 1986).

The consensus of these studies, then, is that compared to wage worker professionals in bureaucracies tended to fare much better and enjoy relatively higher autonomy, meaningfulness, and self-determination even if at times this is accompanied by ambiguity and conflict. However the research on professionals in bureaucracies reached its peak in the 1990s and quickly dissipated as their findings were converging on these points of consensus.

\section{Professionals in Bureaucracies (1995 - Present)}

It is unfortunate that research on professionals in bureaucracies has been so silent since the mid-1990s because professional bureaucracies have changed in significant ways that are likely to have a significant impact on the professional and his or her experience of the work. Whether it is industry, healthcare, law, or education, all of these institutional spheres are being measured and controlled in significantly new ways.

I will name "bureaucracy 1.0" the bureaucratic structure that held sway prior to the introduction of a new bureaucratic element that I will call enterprise-level quality control programs. In the 1990s these programs gained a great deal of traction in professional bureaucracies and included programs such as Lean, Six-Sigma, Information Technology Infrastructure Library (ITIL), and Capability Maturity Model Integration (CMMI). Therefore bureaucracy 2.0 is defined as the new layer of rules, activities, and processes that were previously under the full discretion of the professional but are now being shifted to management or the "process owners."

These programs were philosophically inspired by the Total Quality Management (TQM) and Quality Control (QC) movements of Edward Deming and Juran that were intended to bring tighter controls to the physical production of goods and services. However the newer enterprise-level quality control systems go "up-stream" to processes and activities in the organization that are under the jurisdiction of the professional and hitherto were previously controlled by informal cultural means. While each of these programs differ in some ways from one another, they all 
encroach upon activities that were previously not the target of quantitative measurement and control. All of these programs have demonstrated enough success to be considered industry best practices and therefore have proliferated as organizations adopt them to achieve higher performance or to be seen as legitimate within their organizational fields (DiMaggio \& Powell, 1983). But for our purposes they constitute a new layer of bureaucracy that directly influences the way in which professional work is carried out and evaluated.

Let us now turn our attention to some of the more pervasive and popular programs that have been adopted by professional bureaucracies - all gaining traction in the 1990s.

Lean. Prior to Lean, the Toyota Corporation was grappling with a lack of educated and skilled workers. To overcome this, they strove to capture and document knowledge inherent in various production and development processes (Kimoto, 1991). This evolved into an enterprise level framework for reusing critical process knowledge, the cultivation of expertise at the team level, the use of process visualization techniques, and creating an entrepreneurial culture (Ward, 2007).

Therefore, to the extent that the professional enjoyed a certain level of control and power because of their knowledge prior to Lean, the widespread implementation of Lean shifted some of that control and power to the formal process. This shift in the locus and ownership of professional knowledge represents a new bureaucratic element that I consider a component of bureaucracy 2.0.

Information Technology Infrastructure Library (ITIL). In the 1990s it became clear to the UK government that it was inefficient to have many large bureaucracies addressing the problem of how to implement Information Technology (IT) in response to business strategies and goals. Using W. Edward Deming's Plan-Do-Check-Act (PDCA) cycle, they developed a series of formalized processes to capture the various service elements needed to align IT services with the business strategy and the design of goods and services (Clifford \& van Bon, 2008).

Therefore, as with Lean, the ITIL framework rationalizes and standardizes processes to achieve consistency and efficiency. It is reasonable to assume also that this bureaucratization led to a shift in the tacit process knowledge possessed by IT professionals to the formal process itself that is also characteristic of bureaucracy 2.0 .

Six Sigma. Originally formulated by an engineer from Motorola corporation in 1986, Six Sigma was given great momentum by Jack Welch and its success at GE in the mid-1990s (Adams et. al., 2003). Unlike Lean and ITIL which attempt to capture, codify, and reuse process knowledge, Six Sigma draws upon the TQM process control philosophies in which processes are assumed to have a certain level of "natural" variation and that deviations from those natural levels can be teased out statistically and implicate an unwanted influence or cause in the process that requires correction.

As with TQM, these methods are often applied to the physical/machine processes in manufacturing various products. Unlike TQM, however, Six Sigma is also applied to business processes that include human performance and therefore non-physical (social and psychological) factors. Therefore as "inputs" to these processes, professionals now experience themselves as part of a system in which their knowledge, experience, and skills are monitored and expected to be within established limits. This new control system represents another element of bureaucracy 2.0 .

Capability Maturity Model Integration (CMMI). CMMI was developed by Carnegie Mellon University and the National Defense Industrial Association (NDIA), and, like Six Sigma, strives to monitor existing processes through statistical means (Software Engineering Institute, 2006). However, unlike Six Sigma, CMMI focuses on how well organizations do this and assesses them along a continuum of maturity levels (Siemens, 2013). This approach quickly took hold in the defense contracting industry where contractors could increase their competitiveness if they could advertise to customers that they were assessed to be high in maturity and therefore more likely to demonstrate higher predictability in schedule, budget, and quality performance. Organizations that do not gather data on process performance and have an overreliance on "heroes" to achieve performance are considered to be at maturity level 1. As organizations demonstrate to the certifiers that they are formally defining their processes, gathering process 
performance data, and using this data to improve and optimize their processes, they migrate to higher levels with level 5 (optimizing) being the highest (Software Engineering Institute, 2006).

Therefore, as with Six Sigma, CMMI does attempt to redefine organizational processes, but not with the same intent as Lean and ITIL. Whereas Lean and ITIL strive to capture the tacit professional/occupational knowledge bearing on the processes, Six Sigma and CMMI define the process with the intent to measure its performance. Therefore rather than a shift in power/control from the professional to the bureaucracy due to process knowledge, we instead witness a shift in quality assessment and control. Whereas prior to CMMI professional managers and engineers controlled quality through their informal or semi-formal review processes, CMMI draws upon TQM control chart philosophies to quantify performance into metrics that are used to statistically analyze whether processes are "incontrol" or "out-of-control." If a process is out-of-control special teams are formed to investigate the root causes. Ultimately this shifts the responsibility for quality control from individuals and informal group norms to the formal bureaucratic system. Failure, then, will is framed as a shortcoming in the system that requires tweaking and not the result of individual performance. Rather, failure is assumed to be due to the system mistaking the level of competence of team members or failing to train them to the required levels. While the professional was able to escape the machine or "iron cage" aspects of bureaucracy 1.0, now we see that with bureaucracy 2.0 he or she is now embedded within these control systems.

In summary, then, with both CMMI and Six Sigma, the professional loses some of the responsibility he or she had previously over the evaluation of quality.

\section{ANALYSIS}

Programs similar to Lean, ITIL, Six Sigma, and CMMI are also being proposed and implemented in other institutional spheres such as healthcare, legal practices, and higher education and have been shown to have similar effects on the professional. For example studies show us how the shift in knowledge/skill from the professional to expert systems also create a shift in accountability and control (Bovens, 2002; Burton, 2008; Gilbert, 2005; Constantinides; 2012; Pawlowski, 2004; Levina, 2005).

This represents a systemic bureaucratization of organizations that is shifting the control and power over the work itself, and over the evaluation of quality, away from the professional and into formal processes and their "owners." In addition, the responsibility and accountability quality (performance) shifts from the individual worker and/or group to management. The professional is now no longer to be credited or blamed for organizational performance as these outcomes are now under the orchestration of the formal system and the logic of resource development and allocation. For convenience the key distinctions between bureaucracy 1.0 and 2.0 are compiled in Table 1 .

Table 1: Key Distinctions between Bureaucracy 1.0 and 2.0

\begin{tabular}{|l|l|l|}
\hline \multicolumn{1}{|c|}{ Category } & \multicolumn{1}{c|}{ Bureaucracy 1.0 } & \multicolumn{1}{c|}{ Bureaucracy 2.0 } \\
\hline Quality Control Object & Physical Processes & Business/Social Processes \\
\hline Location of Process Knowledge & Professional Worker & Formal Process \\
\hline Evaluation of Quality & Normative, adaptive & Prescribed, Statistical \\
\hline $\begin{array}{l}\text { Responsibility \& accountability } \\
\text { for Quality }\end{array}$ & $\begin{array}{l}\text { Professional, } \\
\text { Workgroup }\end{array}$ & Management \\
\hline
\end{tabular}

\section{A Call for Critical Study}

As mentioned earlier, at roughly the same time that these enterprise level programs were gaining traction scholarly interest in professionals and bureaucracies had run its course. While some studies have been performed highlighting some these issues in organizations that have implemented CMMI (e.g., Nugent \& Collar, 20014), by and large this significant bureaucratic shift has gone unstudied from critical angles. Yet these general observations beg certain questions. What caused this shift and the widespread emergence of these bureaucratic programs? Did the strong culture paradigm that dominated organizational development in the late 1980s and early 1990s fail to achieve the 
required results? Were informal norms, rites, rituals, and symbols insufficient to motivate professionals or were the negative effects of strong cultures (Kunda, 1992) undermining performance?

Or was it inevitable that in establishing more executive control and power the quality control (TQM, QC) philosophy established by Deming and Juran would move to higher and higher levels of the organization and be applied to business/social processes?

What effects do these shifts have on alienation and deskilling? As we saw with Lean and ITIL, critical process knowledge that was previously within the minds and bodies of the professional were captured and codified into the formal process to the extent possible. While on the one hand this is a rational move by organizations, on the other hand it may reduce the meaningfulness of the work to the professional. Perhaps more interesting is the question of alienation. Determining quality levels and observing/evaluating/correcting process performance has shifted from internalized norms and informal activities in bureaucracy 1.0 to a group of "process owners" in bureaucracy 2.0 that implement and maintain the statistical monitoring systems. Therefore Marxist forms of alienation stemming from an estrangement of these activities from one's own ownership/control can be expected to intensify.

Finally, unlike Marx, Weber believed that the greatest danger of bureaucracy the way in which it rationalizes all human activity. Therefore the alienation stemming from rationalization of work spills far beyond the more narrow sphere of class conflict and capitalism occupying Marx's attention into all bureaucratic spheres such as the military, non-profit organizations, higher education, etc. (Gerth \& Mills, 1946). This compels us to wonder more about the overall psychological effects of bureaucratization/rationalization. For example, according to Robert Jackall's study of corporate managers:

Bureaucratic work shapes people's consciousness in decisive ways. Among other things, it regularizes people's experiences of time and indeed routinizes their lives by engaging them into daily proximity with and subordination to authority, creating in the process upward-looking stances that have decisive social and psychological consequences; it places a premium on a functionally rational, pragmatic habit of mind that seeks specific goals; and it creates subtle measures of prestige and an elaborate status hierarchy that, in addition to fostering an intense competition for status, also makes the rules, procedures, social contexts, and protocol of an organization paramount psychological and behavioral guides. (Jackall, 1988, pp. 5,6).

If bureaucracies have this way of conditioning man then our observations about bureaucracy 2.0 compel us to also entertain notions from the philosophy of technology. In his famous essay The Question Concerning Technology, for example, Martin Heidegger argues that technology strongly affects the way in which man frames being. Unlike the ancient Greeks who focused on the becoming facet of technology, he believes modern technology conditions us to conceive of all objects in our environment (including ourselves and other humans) as resources-at-hand (Heidegger, 1977). This conceals other facets of being such as the inherent value of being independent of utility. Bureaucracy, as a set of rules and institutional structures, can be viewed as a form of technology through which human beings experience their world in different ways. In bureaucracy 2.0 we see an interesting intensification of this dynamic in which the professional now is treated as, and therefore becomes and sees herself, as a measurable source of variation within a formal system and even heroism, the capacity to rise above and respected for one's knowledge and skills in times of crisis, is framed as a system failure.

Other philosophers of technology focus on particular technologies and how they influence our subjectivity. For example, a microscope or a telescope influence what we can see or not see and where our attention will be focused (Ihde, 2010). How, then, does bureaucracy in general, or bureaucracy 2.0 in particular, if we are to view them as technologies, shift our focus or bring certain objects toward the foreground and other objects to the background? Again, as the rationalized structure forces the professional to see himself as source of variation, how does this effect the way in which he will allow himself to be seen? How will he manipulate what can be seen? How will the bureaucracy adapt to overcome this by moving toward the panopticon model highlighted in Foucault's (1977) analysis of penal systems? 


\begin{abstract}
SUMMARY
In summary, this paper is intended to sensitive organizational scholars to the shift that has been occurring in bureaucracies across most, if not all, institutional spheres over the last 25 years or so. Control and power once possessed by and enjoyed by the professional are being shifted into the bureaucracy itself and this may have negative consequences to the professional, and perhaps over time, to the productivity of the organization.
\end{abstract}

\title{
REFERENCES
}

Adams, C. W., Gupta, P., \& Wilson, C. E. (2003). Six sigma deployment. Burlington, MA: Butterworth-Heinemann.

Bailyn, L. (1985). Autonomy in the Industrial R\&D Lab. Human resource management 24: 129-46.

Becker et. al. (1961). Boys in white. Chicago: University of Chicago Press.

Braverman, H. (1974). Labor and monopoly capital. New York: Monthly Review Press.

Bonjean, C. M. \& Grimes, M. D. (1970). Bureaucracy and alienation: a dimensional approach. Social forces. March, Vol. 48, Issue 3, pp. 365-373.

Bovens, M. \& Zouridis, S. (2002). From street-level to system-level bureaucracies: how information and communication technology is transforming administrative discretion and constitutional control. Public administration review 62(2), 174-184.

Burawoy, M. (1979). Manufacturing consent. Chicago: The University of Chicago Press.

Burton, J. \& Van den Broek, D. (2009). Accountable and countable: Information management systems and the bureaucratization of social work. British journal of social work 39(7), 1326-1342

Clifford D. \& van Bon, J. (2008). Implementing ISO/IEC 20000 certification: the roadmap. ITSM Library. Van Haren Publishing.

Constantinides, P. (2012). Accountability in IT-mediated cross-boundary work: insights from a longitudinal case Study. Scandinavian journal of information systems 24(1), Article 2.

Dalton, M. (1959). Men who manage. John Wiley \& Sons, Inc.: USA.

DiMaggio, P. and Powell, W. W. (1983). The iron cage revisited: institutional isomorphism and collective rationality in organizational fields. American sociological review, 48 (April), 147-60.

Foucault, M. (1977). Discipline \& punish: the birth of the prison. Vintage Books, New York.

Gerth, H. H. and Mills, W. M. (1946). From Max Weber: essays in sociology. Oxford University Press.

Gilbert, T. (2005). Trust and managerialism: Exploring discourses of care. nursing and health care management and policy 52(4), pp. 454-63.

Gouldner, A. W. (1954). Patterns of industrial bureaucracy. Glencoe, Ill.

Hall, R. H. (1991). Organizations: structures, processes, \& outcomes. Fifth Edition. Prentice Hall, Inc. Englewood Cliffs, NJ. 
Heidegger, M. (1977). The question concerning technology. In the question concerning technology and other essays. Harper \& Row Publishers.

Ihde, D. (2010). Heidegger's technologies: postphenomenological perspectives. Fordham University Press, New York (2010).

Jackall, R. (1988). Moral mazes. Oxford University Press: New York.

Kanter, R. (1977). Men and women of the corporation. New York: Basic Books.

Kimoto, S. (1991). Quest for the dawn (1st ed.). Dougherty Co.

Kunda, G. (1992). Engineering culture. Temple University Press: Philadelphia.

Levina, N. \& Vaast, E. (2005). The emergence of boundary spanning competence in practice: implications for implementation and use of information systems. Management information systems quarterly 335-363.

Matheson, C. (2007). In praise of bureaucracy? a dissent from Australia. Administration \& society. April, Vol. 39, Issue 2, pp. 233-261.

McGregor, D. M. (1957). The human side of enterprise. Management review, November.

McClelland, D. C. (1966). That urge to achieve. Think magazine. IBM.

Merton, R. K. (1940). Bureaucratic structure and personality. Social forces. 18: 560-568.

Nugent, P. D. \& Collar, E. (2014). The hidden perils of addressing complexity with formal process: a philosophical and empirical analysis. Proceedings of the complex systems design \& management conference. Paris ,France.

Pawlowski, S. D. \& Robey, D. (2004). Bridging user organizations: knowledge brokering and the work of information technology professionals. Management information systems quarterly, 645-672.

Perrow, C. (1986). Complex organizations: a critical essay. Third Edition. McGraw-Hill, Inc.: New York.

Roethlisberger, F. and Dixon, W. (1939). Management and the worker. Cambridge, Mass.: Harvard University Press.

Rohlen, T. (1974). For harmony and strength: Japanese white collar organization in anthropological perspective. Berkeley: University of California Press.

Rosen, M. (1984). Power and culture in bureaucracy: a study of bureaucracy as a control mechanism in monopoly capitalism. Ph.D. dissertation, University of Pennsylvania.

Roy, D. (1954). Efficiency and 'the fix': informal intergroup relations in a piecework machine shop. American Journal of Sociology, 60, pp. 255-66.

Selznick, P. (1949). TVA and the grass roots. Berkeley, CA.

Siemens AG Corporate Technology. (2013). Security by design with CMMI for development. Version 1.3, (May 2013). 


\section{Issues in Information Systems \\ Volume 17, Issue I, pp. 128-135, 2016}

Smith, M. P. (1971). Alienation and bureaucracy: the role of participatory administration. Public administration review, Nov/Dec. Issue 6, pp. 658-664.

Software Engineering Institute (2006). Standard CMMI appraisal method for process improvement (SCAMPISM) A, Version 1.2: Method Definition Document.

Tripathi, B. D. (1976). The alienated actor. Sociological bulletin. Vol. 25, No. 2, pp. 151-167.

Weber, M. (1973). Bureaucracy. Chapter in Classics of organization theory, Shafritz, J. M. \& Ott, J. S. (Eds.) 3rd Ed. Brooks/Cole Publishing Co.: CA.

Ward, A. (2007). Lean product and process development. The Lean Enterprise Institute, Inc.

Whyte, W. (1956). The organization man. New York: Simon and Schuster. 